University of Wollongong

Research Online

Faculty of Engineering and Information

Faculty of Engineering and Information

Sciences - Papers: Part A

Sciences

$1-1-2013$

Comparative analysis of dynamic line rating models and feasibility to minimise energy losses in wind rich power networks

Mathew Simms

University of Wollongong

Lasantha Meegahapola

University of Wollongong, lasantha.meegahapola@rmit.edu.au

Follow this and additional works at: https://ro.uow.edu.au/eispapers

Part of the Engineering Commons, and the Science and Technology Studies Commons

Research Online is the open access institutional repository for the University of Wollongong. For further information contact the UOW Library: research-pubs@uow.edu.au 


\title{
Comparative analysis of dynamic line rating models and feasibility to minimise energy losses in wind rich power networks
}

\begin{abstract}
Wind power generation has indicated an exponential increase during last two decades and existing transmission network infrastructure is increasingly becoming inadequate to transmit remotely generated wind power to load centres in the network. The dynamic line rating (DLR) is one of the viable solutions to improve the transmission line ampacity during high wind penetration without investing on an additional transmission network. The main objective of this study is to identify the basic differences between two main line rating standards, since transmission network service providers (TNSPs) heavily depend on these two standards when developing their line rating models. Therefore, a parameter level comparison between two line rating models is a timely requirement, in particular for high wind conditions. Study has shown that roughness factor causes a significant difference between both standards. In particular, the IEEE model indicates more conservative approach due to this parameter. In addition, solar heat-gain calculation has also resulted in significant difference in ampacity ratings between two standards. A case study was developed considering a wind rich network and it has shown that by implementing DLR in wind rich regions, it can effectively reduce line overloading incidents and accommodate wind power flows in the network without any curtailment. Moreover, ability of DLR to reduce network energy losses is also demonstrated and emphasised the importance of selecting suitable DLR candidates to minimise energy losses in the network. (c) 2013 Elsevier Ltd. All rights reserved.
\end{abstract}

\section{Keywords}

rating, power, rich, wind, losses, energy, minimise, feasibility, dynamic, comparative, analysis, networks, models, line

\section{Disciplines \\ Engineering | Science and Technology Studies}

\section{Publication Details}

M. Simms \& L. Meegahapola, "Comparative analysis of dynamic line rating models and feasibility to minimise energy losses in wind rich power networks," Energy Conversion and Management, vol. 75, pp. 11-20, 2013. 


\title{
Comparative Analysis of Dynamic Line Rating Models and Feasibility to Minimise Energy Losses in Wind Rich Power Networks
}

\author{
Mathew Simms, Lasantha Meegahapola ${ }^{+}$ \\ School of Electrical, Computer and Telecommunications Engineering, \\ University of Wollongong, Wollongong, 2500, Australia.
}

\begin{abstract}
Wind power generation has indicated an exponential increase during last two decades and existing transmission network infrastructure is increasingly becoming inadequate to transmit remotely generated wind power to load centres in the network. The dynamic line rating (DLR) is one of the viable solutions to improve the transmission line ampacity during high wind penetration without investing on an additional transmission network. The main objective of this study is to identify the basic differences between two main line rating standards, since transmission network service providers (TNSPs) heavily depend on these two standards when developing their line rating models. Therefore, a parameter level comparison between two line rating models is a timely requirement, in particular for high wind conditions. Study has shown that roughness factor causes a significant difference between both standards. In particular, the IEEE model indicates more conservative approach due to this parameter. In addition, solar heatgain calculation has also resulted in significant difference in ampacity ratings between two standards. A case study was developed considering a wind rich network and it has shown that by implementing DLR in wind rich regions, it can effectively reduce line overloading incidents and accommodate wind power flows in the network without any curtailment. Moreover, ability of DLR to reduce network energy losses is also demonstrated and emphasised the importance of selecting suitable DLR candidates to minimise energy losses in the network.
\end{abstract}

Keywords: Ampacity, convection cooling, dynamic line rating (DLR), energy losses, joule heating, radiated cooling, roughness factor, solar heating, wind generation.

+Corresponding author: Tel: +61 24221 3408, e-mail: lasantha@uow.edu.au. 


\section{Introduction}

Ampacity is used to describe the maximum current carrying capacity of an overhead transmission line which is directly related to the temperature of the conductor. Ampacity is usually calculated considering static weather conditions, which utilises worst case weather parameters in order to determine the maximum current the conductor can handle without exceeding the temperature limits. The consequences of exceeding this temperature limit can be detrimental as the conductor can sag enough to cause an arc fault to earth, or become permanently deformed and require replacement. Therefore, static line ratings (SLRs) have been designed in such a way to conservatively rate the conductors to minimise the possibility of these faults. The dynamic line ratings (DLRs) have been determined considering the real time weather data and now being received immense attention from power industry with the increased wind penetration in power networks.

Two major standards (i.e. IEEE and CIGRE) are being used for SLR and DLR to determine the conductor ampacity [1]-[2]. Both standards incorporate the convection cooling, the radiated cooling, the solar heating and the conductor electrical resistance (i.e. Joule heating) to accurately calculate the ampacity of the line, and conversely, the temperature of a line at a specified current. Transmission network service providers (TNSPs) have also designed thermal rating standards, which have branched specifically from the CIGRE and the IEEE standards. However, very limited number of studies have analysed the difference between these two standards considering individual parameters [3-4]. In particular, two standards have been analysed considering measured data without investigating the parameters influencing the line rating [4]. However, differences between the two standards, in terms of individual parameters have not been taken place. Moreover, a limited number of studies are performed at high wind speeds which may have a considerable effect on line rating when significant wind penetration present in a power network.

Wind turbines are installed in remote regions in power network and it has been emphasised that transmission corridors become congested due to increased penetration levels of renewable energy generators [5]. In number of studies transmission congestion has been identified as the major curtailing factor for wind power generation [6-7] and requires considerable time and investment to develop a new transmission network. The convection cooling of the conductors will be at its highest during times of high wind generation assuming high wind speeds experienced at transmission lines, hence wind cooling effect can be effectively utilised without implementing 
expensive transmission network upgrade. Weather deterministic ampacity ratings (i.e. DLR) utilise weather data obtained from weather stations located in the vicinity of the overhead line. Typically, wind direction, wind speed, ambient temperature, conductor temperature and solar ambience are taken and sent to a control centre for further analysis. From these values, the real time ampacity ratings based on conductor temperature are determined, and the power to be sent down the line can be controlled and maintained at the most effective level.

The main issue with the DLR is quality of data [8-9]. The wind attack angle and the wind speed affecting a transmission line is not always a constant for long distance lines, hence current methods for calculation the DLR become unsuitable $[8,10]$. This can cause large variance between the ampacity ratings for a line at various positions [11]. In another study, real time measurements are taken from four locations along a transmission line and they were reasonably similar [12], which indicate that one set of data may accurately represent the entire line. Based on preliminary judgement, the vastness of the transmission network to be analysed will greatly depends on the suitability of the weather deterministic model, and the extent to which data is collected. In [13], authors have developed a statistical model using measured data in a transmission line and demonstrated the potential of DLR in a wind rich power network. The conductor sag based dynamic line rating models have also been investigated in the published literature [14-15]. Furthermore, potential of DLR to reduce system losses have also been demonstrated in [16], assuming all transmission lines have DLR capability.

The main objective of this study is to illustrate the parameters which cause major differences between the two line rating standards and to illustrate the potential of utilising the dynamic line rating (DLR) in wind rich power networks to reduce network energy losses. A parameter level comparison is a timely requirement, since it will enable utilities to identify and tune the existing line rating models suit to their network. In addition, DLR can be implemented in wide-scale in a smart transmission system; hence network losses can be effectively reduced while coordinating the power flows in the network. This paper is organised as follows: The basic parameter level differences between two line rating models are discussed in Section 2. A comparison between two models considering various parameters is presented in Section 3. A sensitivity analysis between various parameters of the IEEE model is presented in Section 4. A case study based on the New England-39 bus system to illustrate the benefits of the DLR is presented in Section 5. The conclusions of the study is summarised in Section 6. 


\section{The IEEE and the CIGRE Dynamic Line Rating Models}

A number of physical factors of the conductor and of the surrounding environment affect the total ampacity of a conductor. These are conductor material properties, conductor diameter, conductor surface conditions, and ambient weather conditions [5]. The SLR of a current carrying conductor is based on a worst case set of criteria, including limited wind speed and maximum conductor temperature (due to current flow) [17]. These worst case values are used to ensure that there is a significant room in the event of substantially different weather conditions and conductor parameters. The IEEE [1] and the CIGRE [2] standards are the two major frequently used industry standards to determine the maximum current capacity of overhead transmission lines. Each standard is based on a fundamental heat balance equation. However, there exist some differences when determining various contributing factors to the final ampacity rating of the conductor. Equations (1) and (2) depict the basic heat balance formulas specified by the IEEE and the CIGRE standards respectively.

$P_{c}+P_{r}=P_{S}+P_{J}$

$P_{c}+P_{r}+P_{w}=P_{S}+P_{J}+P_{M}+P_{i}$

$P_{c}, P_{r}, P_{S}, P_{J}, P_{w}, P_{M}$ and $P_{i}$ denote convection heat loss, radiated heat loss, solar heat gain, conductor joule heating, evaporative cooling, magnetic heating and corona heating respectively. The CIGRE standard incorporates additional parameters to that of the IEEE standard, which include corona heating $\left(P_{i}\right)$, magnetic heating $\left(P_{M}\right)$ and evaporative cooling $\left(P_{w}\right)$. Minimal references can be found on the effects of these parameters; however it is stated in [3] that only a very small fraction of corona heating is passed into the conductor. Although the CIGRE standard mentioned evaporative cooling, it does not outline any method for its calculation [2]. Therefore, in this study, same general heat balance equation has been used for both the IEEE and the CIGRE standards. Eqn. (1) can be rearranged in order to determine the ampacity (I) as shown in Eqn. (3).

$I=\sqrt{\frac{P_{c}+P_{r}-P_{s}}{R\left(T_{c}\right)}}$

Therefore, fundamental components will be used to make a comparison between the two standards. In following subsections a comparison between the IEEE and the CIGRE calculation methods for convection heat loss, solar heat gain and radiated solar heat loss are discussed and 
thus for brevity the formulas for calculating each of the components is not presented in this paper.

\subsection{Convection Cooling}

Convection heat loss is concerned with the removal of heat due to the presence of wind surrounding the conductor. The IEEE standard utilises two formulas to determine the convention cooling effect; one for low wind speeds and another for high wind speeds. However, irrespective of the wind speed the largest value from two formulas is selected for ampacity calculation. The CIGRE equivalent of these equations is slightly different, however based on the same fundamental physical laws. The CIGRE standard defines a Nusselt number $\left(N_{u}\right)$ which is defined as the ratio of convective and conductive heat transfer at the boundary for the conductor. The constants (i.e. $B_{1}, n$ ) which determines the $N_{u}$, is based on the Reynolds number and the surface roughness $\left(R_{f}\right)$ of the conductor. The CIGRE model factors in the surface roughness of the conductor, which further increases the forced convection effect on the conductor. In light of this point, the IEEE standard can be considered as the more conservative method for convection cooling calculation. Neither the IEEE nor CIGRE standard takes into account the dynamic nature of wind speed with regard to pressure differentials and height variations. In most cases, the weather data is obtained at a different height to that of the transmission line, which could mean a slight variation in the true wind speed acting on the line. This could be considered a means of factoring in safety in the ampacity calculations. Furthermore, both standards have given formulas for the natural convective cooling and it will not be considered in this study, since this study focuses on wind speeds above $0 \mathrm{~m} / \mathrm{s}$.

\subsection{Solar Heat Gain}

The solar heat gain determines the effect on conductor temperature due to solar irradiation. Both standards outline similar approach in determining the solar heat gain by a conductor; however, the IEEE method utilises certain correction factors based on conductor elevation from the sea level. In both methods the global solar radiation $(S)$ for a particular location is taken into account, and as stipulated in both standards, it can be easily determined by using a measuring apparatus.

Therefore, CIGRE standard dictates another complex method for solar heat gain calculation. This formula primarily determines the direct solar radiation $\left(I_{D}\right)$ and diffuse solar radiation $\left(I_{d}\right)$, 
while incorporating solar altitude $\left(H_{s}\right)$ and angle of the solar beam $(\eta)$ [2]. This standard also incorporates an albedo factor $(F)$, which is the reflectance of the solar intensity off the ground. This is one of the differences compared to the IEEE standard, and for the purpose of the analysis this was kept at 0.2 to resemble soil, grass or crops.

For the purpose of the initial comparison between the two standards, standard formula in CIGRE would not be suitable as the global solar radiation $(S)$ values are not known. Therefore, the complex method for determining solar heating is used. For both standards the global solar radiation is calculated based on time of day, day of year, latitude of conductor and the solar azimuth of the conductor. Conversely, the IEEE standard outlines a step by step procedure to first determine the global solar radiation $(S)$ which is then applied to standard formula in the IEEE standard to determine the solar heat gain.

\subsection{Radiated Cooling}

For both the IEEE and the CIGRE standards, the radiated heat loss is considered to be a small contributor to the overall heat balance equation. Fundamentally both standards calculate the radiated cooling effect in the same manner. However, the CIGRE formula has an additional component known as Stephan-Boltzmann $\left(\sigma_{B}\right)$ constant. However, both formulas provide the same radiated heat loss for given conditions.

\subsection{Conductor Joule Heating}

The Joule heating of a conductor is due to heat generated when current passes through the conductor. Both the IEEE and the CIGRE standards determine the resistance of the line using linear interpolation, based on DC resistance values at $20^{\circ} \mathrm{C}$ for the CIGRE, and $25^{\circ} \mathrm{C}$ and $75^{\circ} \mathrm{C}$ for the IEEE. The main difference between the Joule heating calculations is that CIGRE provides a conversion method between the $\mathrm{DC}$ and the $\mathrm{AC}$ resistance, which is not prevalent in the IEEE standard. 


\section{Comparison of IEEE and CGRE Models}

A comparative analysis was carried out between the IEEE and the CIGRE standards in order to determine which parameters cause the difference between two standards. As discussed in the previous section the convection cooling and solar heat gain are the two main calculations which may give rise to difference between the two standards. Therefore, discussion of this section is limited only to parameters which cause significant difference between two standards. It is assumed that conductor is aluminium conductor steel-reinforced (ACSR) type and all the test parameters for the base case condition are given in the Appendix A. Furthermore, it is assumed that sky conditions are clear for solar heat gain calculations.

\subsection{Comparison of Convection Cooling Effect}

Variation of the ampacity with the wind speed was analysed by considering the convection cooling, hence all the other factors remained unchanged for both standards. A wind speed was varied from $1 \mathrm{~m} / \mathrm{s}$ to $15 \mathrm{~m} / \mathrm{s}$. Figure 1 depicts the effect of varying wind speed on the ampacity of the line.

According to Figure 1, the wind speed was varied from $0.5 \mathrm{~m} / \mathrm{s}$ to $15 \mathrm{~m} / \mathrm{s}$ in order to cover the complete power generation spectrum of a typical wind turbine generator. A number of studies have compared the IEEE and the CIGRE standards, and the wind speed range was varied from 0 $\mathrm{m} / \mathrm{s}$ to $3 \mathrm{~m} / \mathrm{s}$ [4],[18]. This is an unrealistic assumption to be made for the purpose of this study considering a vast majority of wind generators have a 'cut-in' speed of $4 \mathrm{~m} / \mathrm{s}$. It is assumed that the DLR is implemented to a power network with significant wind penetration; hence it must be validated against a wider spectrum of wind speeds.

The ampacity between two standards tend to vary considerably as the wind speed increases, with a maximum difference between the two curves reaching as high as $459.5 \mathrm{~A}$ when a wind speed of $15 \mathrm{~m} / \mathrm{s}$ was used. The ampacity at low wind speeds for the two standards is relatively consistent; however from $3.5 \mathrm{~m} / \mathrm{s}$ the deviations begin to increase dramatically. The reason for this is related to the roughness factor $\left(R_{f}\right)$ of the conductor. In Figure 1, the roughness factor was 0.08 , which assigns values of 0.178 and 0.633 for coefficients $B_{l}$ and $n$ respectively when determining the scaled Nusselt Number $\left(N_{u}\right)$ in the CIGRE standard [2]. Figure 2 depicts the ampacity variation using a roughness factor of 0.04 . 
As shown in Figure 2, the similarities between the calculated ampacity values are far greater, with a maximum difference between the two ampacity standards reaching $79 \mathrm{~A}$. In comparison to the previous test, the maximum difference occurred at lower wind speeds, while the difference has decreased at higher wind speeds. The average difference was found to be $38.56 \mathrm{~A}$, which is considerably lower to that calculated with a higher roughness factor. Therefore, the roughness factor utilised in the CIGRE standard was set to 0.04, to make a comparative analysis between other influencing factors on ampacity. The other differences between the two standards can be attributed to the solar heating and the resistance calculation of the conductor.

The convection cooling formula is comprised of number of other parameters. Therefore, the parameters of the convection cooling equation have been analysed at three different wind speeds; $0.5 \mathrm{~m} / \mathrm{s}, 4 \mathrm{~m} / \mathrm{s}$ and $8 \mathrm{~m} / \mathrm{s}$ to provide a broader analysis of possible variations in the convection cooling formula.

\subsubsection{Ampacity and Wind Attack Angle}

The wind attack angle has been changed over a range for both standards and analysed the variation of ampacity while maintaining the other test conditions constant. Figure 3 depicts the effect of the wind attack angle on the conductor with respect to ampacity rating.

The ampacity values for both standards depict almost same variation, with an average difference in ampacity between the standards are $22.48 \mathrm{~A}, 37.79 \mathrm{~A}$ and $17.92 \mathrm{~A}$ at $0.5 \mathrm{~m} / \mathrm{s}, 4$ $\mathrm{m} / \mathrm{s}$ and $8 \mathrm{~m} / \mathrm{s}$ respectively. At higher wind attack angles, the difference in the total ampacity rating has showed a significant decrease when compared to lower wind speeds. This is related to the angle constant multiplier which was similar between the two standards from $0^{\circ}$ to $52^{\circ}$, however, IEEE values decrease significantly beyond this range. In the CIGRE standard, the effect of the angle of the wind is purely conditional based on whether it is greater than or less than $24^{\circ}$, conversely in the IEEE standard constant multiplier continually change based on the wind attack angle. 


\subsubsection{Effect of Transmission Line Diameter on Ampacity}

A typical range of cable sizes was sourced from a transmission line manufacture in order to determine the maximum and minimum typical transmission line diameter values [19]. Figure 4 depicts the effect of variation of diameter on ampacity under different wind speeds.

An increase in cable diameter depicts an overall increase in the ampacity of the line. In both standards, convection cooling, radiation cooling and the overall power losses are directly related to the cable diameter. The average difference between the two standards was reasonably low, with a difference of $24.36 \mathrm{~A}, 42.26 \mathrm{~A}, 20.53 \mathrm{~A}$ at $0.5 \mathrm{~m} / \mathrm{s}, 4 \mathrm{~m} / \mathrm{s}$ and $8 \mathrm{~m} / \mathrm{s}$ respectively. However, these differences can be considered as insignificant in comparison to the total current carrying capacity of the conductor.

\subsection{Effect of Ambient Temperature on Ampacity}

As shown in Figure 5, the overall effect of ambient temperature is the same for all three wind speed categories, with each showing a lower ampacity rating as the ambient temperature increases.

At a higher wind speed, the effect of the ambient temperature was greater, and has shown a steep slope at a wind speed of $8 \mathrm{~m} / \mathrm{s}$. At a roughness factor of 0.04 , the average difference between the ampacity values was $16.84 \mathrm{~A}, 43.26 \mathrm{~A}, 22.15 \mathrm{~A}$ for $0.5 \mathrm{~m} / \mathrm{s}, 4 \mathrm{~m} / \mathrm{s}$ and $8 \mathrm{~m} / \mathrm{s}$ respectively. For both standards, the ambient temperature has a considerable effect on the convection cooling, as the difference between the ambient and conductor temperatures is a multiplier factor in the Nusselt number calculation. The ambient temperature also directly affects the radiated heat loss. Heat will transfer from areas with high heat to low heat, hence lower ambient temperature result in a higher radiated cooling.

\subsection{The Variation in Solar Heating Calculation}

A comparison between the IEEE and the CIGRE solar heat gain equations was also carried out, since solar heat gain has resulted in some discrepancy between the two standards when calculating the ampacity of the line. As mentioned in Section 2, the CIGRE standard outlines two formulas which can be used depending on the available information provided by specialised equipment. The base case conditions outlined in Table 1 have been used for the analysis. 
Table 1: Base conditions used to determine the solar heat gain

\begin{tabular}{|c|c|}
\hline Parameter & Value \\
\hline Cable Diameter & $28.11 \mathrm{~mm}$ \\
\hline Latitude & $30^{\circ}$ \\
\hline Conductor Elevation & $100 \mathrm{~m}$ \\
\hline Day of Year & $10^{\text {th }} \mathrm{June}$ \\
\hline Time of Day & $11 \mathrm{am}$ \\
\hline Sky Conditions & clear \\
\hline Solar Absorptivity & 0.5 \\
\hline
\end{tabular}

To perform this test, the IEEE standard was used as the reference to calculate the global solar radiation. This value was then used in the CIGRE basic solar heating formula to determine the CIGRE equivalent of the solar heating power absorbed. The calculated values for both standards were similar (e.g. IEEE-14.567 W/m and CIGRE-14.6031 W/m). Unlike in the IEEE formula, basic CIGRE formula for solar heating does not factor in the effective angle of incidence of the sun's rays, which is accountable for the very small variation between the two values.

Therefore, in these simulations basic CIGRE formula has not been used, since global solar radiation data was not provided, and it was considered more beneficial to test the respective complex processes outlined in both standards. The complex solar heating formula of the CIGRE standard has depicted a value of $20.25 \mathrm{~W} / \mathrm{m}$, which is significantly different compared to the IEEE standard.

\subsubsection{Comparison of Solar Heat Gain: Ampacity and Elevation}

Conductor elevation directly affects the solar heat gain in line rating models, and hence its impact was analysed while increasing the conductor elevation from $0 \mathrm{~m}$ to $1600 \mathrm{~m}$ from sea level. Figure 6 depicts the overall effect of conductor elevation with regards to ampacity.

As illustrated in Figure 6 at each of the three wind speeds, a linear downward trend can be observed. The variation of conductor elevation affects two major parameters. The elevation of the conductor directly decreases the relative air density surrounding the conductor, which has a direct negative impact on the convection cooling of the conductor. At a higher elevation, the effect of the solar radiation increases due to the solar heat multiplier. The average difference 
between the two standards with changing elevation was found to be $10.52 \mathrm{~A}, 39.16 \mathrm{~A}$ and 20.51 A at $0.5 \mathrm{~m} / \mathrm{s}, 4 \mathrm{~m} / \mathrm{s}$ and $8 \mathrm{~m} / \mathrm{s}$ respectively.

The comparative analysis indicates that the IEEE and the CIGRE equations produce almost similar conductor ampacity ratings, when the influence of the roughness factor is ignored. In addition, major variations between two standards are also resulted in due to the solar heat gain calculation, which has shown substantial variations in their final ampacity values. However, the highest difference is around $10 \%$, and for the further studies the IEEE standard has been used. 


\section{Sensitivity Analysis}

A sensitivity analysis was carried out on IEEE equations in order to determine the major contributing factors for the transmission line ampacity. The following formula has been used to calculate the overall percentage change of the ampacity when compared to base case conditions.

$$
\text { Sensitivity }=\left[\frac{(\max \text { Ampacity }-\min \text { Ampacity })}{\min \text { Ampacity }}\right] \times 100 \%
$$

Table 2 depicts the relative percentage change for each of the parameters at three different wind speeds (i.e. $0.5 \mathrm{~m} / \mathrm{s}, 4 \mathrm{~m} / \mathrm{s}$ and $8 \mathrm{~m} / \mathrm{s}$ ).

Table 2: Results of sensitivity analysis

\begin{tabular}{|c|c|c|c|c|}
\cline { 3 - 5 } \multicolumn{2}{c|}{} & \multicolumn{3}{c|}{ Wind Speed } \\
\hline Parameter & Range & $0.5 \mathrm{~m} / \mathrm{s}$ & $4 \mathrm{~m} / \mathrm{s}$ & $8 \mathrm{~m} / \mathrm{s}$ \\
\hline Wind Angle & $\left(0^{\circ}\right.$ to $\left.90^{\circ}\right)$ & $47.35 \%$ & $29.21 \%$ & $24.13 \%$ \\
\hline Elevation & $(0 \mathrm{~m}$ to $1600 \mathrm{~m})$ & $-7.11 \%$ & $-4.13 \%$ & $-3.37 \%$ \\
\hline Cable Diameter & $\left(15 \mathrm{~mm}^{2}\right.$ to $50 \mathrm{~mm}^{2)}$ & $40.55 \%$ & $24.11 \%$ & $19.69 \%$ \\
\hline Ambient Temperature & $\left(10^{\circ} \mathrm{C}^{\circ}\right.$ to $\left.50^{\circ} \mathrm{C}\right)$ & $-37.36 \%$ & $-21.67 \%$ & $-17.70 \%$ \\
\hline
\end{tabular}

Wind angle indicated the highest overall percentage change at each wind speed in comparison to the other parameters. The overall percentage change for wind angle at $8 \mathrm{~m} / \mathrm{s}$ was $24.13 \%$, which is significantly higher than the other parameters. Conductor elevation proved to have the least impact on the overall ampacity when increased from $0 \mathrm{~m}$ to $1600 \mathrm{~m}$ with the maximum change is only $-7.11 \%$. This downward trend was witnessed at all wind speeds and this is related to the increasing rate of solar heating at high temperatures. Moreover, it has been observed that the elevation of the conductor has a greater impact on solar heating than on convection cooling.

Ambient temperature and cable diameter showed similar absolute ampacity changes at all wind speeds. As expected, the ambient temperature has indicated a downward trend as the ambient temperature increased from $10^{\circ} \mathrm{C}$ to $50^{\circ} \mathrm{C}$. This is related to the fact that radiated cooling and convection cooling is directly related to the difference between conductor and ambient temperature. As this difference becomes smaller, the rate at which the conductor can remove heat has decreased. The cable diameter showed an opposite trend, as the rate of convection cooling and radiated cooling increase due to the diameter of the conductor. 
Furthermore, sensitivity analysis has indicated that at higher wind speeds, the variation of these parameters has a lesser effect than at lower wind speeds. It should also note that at higher wind speeds, the dynamic line rating is less affected by other factors which could result in a more stable ampacity value. Typically, wind speed is highly variable, and a consistent wind speed is very unlikely. However, sensitivity analysis has shown that with the abundance of high wind speed, convection cooling is at its highest and does in fact drive the ampacity of the line. 


\section{Case Study: Feasibility of DLR in Wind Rich Power Networks}

The New England 39 bus system was utilised in order to analyse the performance of the DLR during high wind conditions. The simulated system is comprised of five regions, in which Area 1 was the focus of this study. Area 1 consists of 10 buses, and a total of 8 lines with ampacity ratings between $0.5 \mathrm{kA}$ and $3 \mathrm{kA}$. The ampacity values of the transmission lines and their corresponding resistance values have been previously determined and they have been utilised as base case values for future calculations. It should be noted that these tests consider steady-state line rating models and performed as statistical static load-flow tests in order to illustrate the benefits of the DLR in wind rich network. Figure 7 illustrates a schematic of the New England 39 bus system.

All tests have been carried out using DIgSILENT Power Factory. In each of the ten buses within Area 1 of the New England system a wind farm was connected with the characteristics similar to the GE $1.5 \mathrm{MW}$ wind turbine while each wind farm is comprised of 100 parallel connected GE $1.5 \mathrm{MW}$ wind generators. This turbine has a cut-in wind speed of $3 \mathrm{~m} / \mathrm{s}$ and can produce 1.5 MW at wind speeds on or above $14 \mathrm{~m} / \mathrm{s}[20]$.

\subsection{Determining Suitable DLR Candidates}

Two static tests have been performed during high wind conditions in order to determine transmission lines suitable for DLR implementation. The first test was conducted by incrementally increasing the power output of an individual wind farm installed at each of the buses in Area 1, while the second test was performed by incrementing the power output of all wind farms at the same time. The algorithm was coded in DIgSILENT DPL in order to determine the number of overloading incidents for each line for a given loading condition:

Overloading incidents for line $i=\underbrace{\sum_{n=1}^{k}\left(\sum_{n=1}^{j}\left(\forall L_{i} \in L: L_{i}>L_{\max }\right)\right)}_{\text {test } 1}+\underbrace{\sum_{n=1}^{j}\left(\forall L_{i} \in L: L_{i}>L_{\max }\right)}_{\text {test } 2}$

$j$ - no. of power output iterations for a wind farm, $k$ - no. of buses in area 1

Figure 8 illustrates number of overloading incidents reported for transmission lines in area 1. The results of the two tests at $100 \%$ and $80 \%$ were collated together, in order to see which lines in the network are susceptible to overloading at their current static rating. It should be noted that lines with only significant number of overloads are shown in Figure 8. 
Line 3-18 has indicated the highest number of overloading incidents, with a total of 39 in test 1 and 9 in test 2 at 100\% load demand. At $80 \%$, the number of overloading cases has been increased with a total of 192 for test 1 and 32 for test 2. It is in light of this point that line 3-18 was the first to be chosen to implement the DLR. This line has a base case ampacity of $0.5 \mathrm{kA}$ with a resistance of $0.11 \Omega / \mathrm{km}$. The remaining two lines chosen for DLR implementation are lines 17-18 and 17-27. Line 17-27 was chosen due to its relatively high overloading incidents with a total of 139 . It was also sited in close proximity to line 3-18. Line 17-18 was chosen as an outlier, since its overloading incidents was much less than the other two lines. The ampacity values for these two lines were $0.5 \mathrm{kA}$ and $1.6 \mathrm{kA}$ with resistances of $0.13 \Omega / \mathrm{km}$ and $0.07 \Omega / \mathrm{km}$ respectively. Although, line 2-25 has indicated high overloading incidents due to local wind generation that has been ruled out due to practical reasons, since wind generation is very unlikely to site in close proximity to conventional generation.

The overall overloading incidents have been increased when the load demand was scaled down from $100 \%$ to $80 \%$. For example, in test 1 at $100 \%$ loading, three lines showed a total of 81 overloading incidents, and in contrast, at $80 \%$ loading the number of overloading incidents has been increased by a factor of four, with a collective total count of 325 overloading incidents. This can be linked to the fact that when load demand is scaled down, the excess power within area 1 increases, since wind generation remains unchanged. This results in a large number of overloading incidents in certain lines in the network, in particular at main export corridors of the network. For example, line 1-2 showed no overloading incidents for test 1 at $100 \%$ load demand, however, at $80 \%$ load demand a number of overloading incidents have been reported as it is the main export corridor to other regions of the New England (NE)-39 bus system.

\subsection{Estimated Dynamic Line Ratings with Varying Wind speed}

The dynamic line ratings for transmission lines $3-18,17-27$ and $17-18$ determined using the IEEE standard. The rated ampacity values of the original NE-39 bus system were used as base conditions at an assumed ambient temperature of $25^{\circ} \mathrm{C}$. Table 3 lists the assumed ideal conditions, which would be the base values at which all resistance and diameter values are calculated. Table 3 also outlines the current Australian Energy Market Operator (AEMO) rating standards [21] and they have been utilised to test the DLR performance during summer, winter and spring months. The middle date of each season was used to determine the solar heating. 
Table 3: Weather characteristics at ideal, winter, summer and spring conditions

\begin{tabular}{|c|c|c|c|c|}
\hline Parameter & Ideal & Summer & Winter & Spring \\
\hline Ambient Temp $\left({ }^{\circ} \mathrm{C}\right)$ & 25 & 40 & 38 & 33 \\
\hline Wind Attack Angle $\left({ }^{\circ}\right)$ & 90 & 90 & 90 & 90 \\
\hline Elevation $(\mathrm{m})$ & 0 & 0 & 0 & 0 \\
\hline Time of Day & 11 am & 11 am & 11 am & 11 am \\
\hline Sky Condition & Clear & Clear & Clear & Clear \\
\hline Direct Solar Radiation $\left(\mathrm{W} / \mathrm{m}^{2}\right)$ & 0 & 1000 & 900 & 500 \\
\hline
\end{tabular}

The maximum allowable temperature of the transmission line was assumed to be $80^{\circ} \mathrm{C}$ when it carries its full rated capacity for seasonal conditions. This was kept constant for all conditions, including the ideal conditions with an ambient temperature of $25^{\circ} \mathrm{C}$. The dynamic ratings of line $3-18,17-18$, and 17-27 were calculated at each wind speed provided by the power versus wind speed curve of the GE 1.5 MW wind turbine [20]. Figure 9 depicts the relationship between wind speed and ampacity for each of the four seasonal conditions for line 3-18.

As expected, due to high ambient temperature difference, the ideal condition has indicated the greatest variation in the ampacity at all wind speeds. This was followed by winter, spring and summer due to the decreasing difference between the ambient and the conductor temperature. Although solar heating is different from one season to another, it has indicated a minimal impact on the overall ampacity of the line due to high convection cooling during high wind conditions. This correlates with the results of the sensitivity analysis of the IEEE standard (Section 4).

\subsection{Applying DLR to the lines - Ideal Case}

Five buses (i.e. buses 3,18, 17 and 27) were chosen to have wind farms and their locations were based with respect to transmission lines $3-18,17-18$ and 17-27. Bus 1 was chosen as it has the highest overloading incidents, in particular, with line 3-18. For the tests to follow, all possible combinations of wind farms were tested at each of the dispatch power levels shown by the power versus wind speed curve of the wind turbine [20]. Similar to that in Section 5.1, a transmission line was considered overloaded if the magnitude of the current through the line exceeds the nominal ampacity of the line. The overall overloading incidents for each of these 
lines were first tested without DLR, at $100 \%$ and $80 \%$ loading. Figure 10 depicts the total overloading incidents of the lines without implementing the DLR.

It can be seen that line 3_18 depicts the highest prevalence of overloading with total incidents of 94 cases at $100 \%$ load and 248 cases at $80 \%$ load. Line $17-27$ has indicated the second highest overloading incidents with 25 cases and 131 cases at $100 \%$ and $80 \%$ loading respectively. Finally, line $17-18$ has indicated 7 and 230 line overloading incidents at $100 \%$ and 80\% load demand respectively. Therefore, these lines are suitable candidates for DLR implementation.

The calculated dynamic ratings for lines $3-18,17-18$ and $17-27$ were then applied to the network in order to analyse the impact of DLR on line overloading. In this analysis, all combinations of wind generators were tested assuming ideal wind conditions (i.e. wind speed at the wind generator was same as at the transmission line).

At $100 \%$ load demand, all three lines indicated no overloading incidents when DLR was applied. However, at $80 \%$ load demand two lines have considerably overloaded (see Figure 11). Line 17-27 indicated no overloading incidents at $80 \%$ load demand across all seasonal conditions. At ideal conditions lines 3-18 and 17-18 have indicated the greatest improvement in line overloading with overloading incidents decreased by 109 and 224 for lines 3-18 and 17-18 respectively. At three seasonal conditions the reduction for these lines was not as pronounced. As expected, overloading incidents for all three transmission lines from summer to winter did decrease due to the greater difference between transmission line conducting temperature and ambient temperature. However, there are some significant differences between ideal and winter conditions, which could indicate a highly conservative assumption for the average ambient temperature during the winter months.

\subsection{Applying the DLR with Wind Gradient along the Line}

The DLR system implemented in the NE-39 bus system was reapplied assuming more realistic wind conditions at transmission lines. The line ratings at $2 \mathrm{~m} / \mathrm{s}, 6 \mathrm{~m} / \mathrm{s}$ and $9 \mathrm{~m} / \mathrm{s}$ were determined and then assigned to the lines statically to simulate the possibility of varying wind speed across the line, and also different wind speed to that occurring at the wind turbine itself. The ratings were determined again at ideal, summer, winter and spring seasons, in order to obtain a more accurate representation of the performance of DLR on such system. The study has 
also analysed $100 \%$ and $80 \%$ loading scenarios in order to make a comparison with previous tests. Table 4 depicts the calculated ampacity at an ambient temperature of $25^{\circ} \mathrm{C}$.

Table 4: Transmission line ratings at $2 \mathrm{~m} / \mathrm{s}, 6 \mathrm{~m} / \mathrm{s}$ and $9 \mathrm{~m} / \mathrm{s}$

\begin{tabular}{|c|c|c|c|}
\cline { 2 - 4 } \multicolumn{1}{c|}{} & \multicolumn{3}{c|}{ Wind Speed } \\
\hline Line Number & $2 \mathrm{~m} / \mathrm{s}$ & $6 \mathrm{~m} / \mathrm{s}$ & $9 \mathrm{~m} / \mathrm{s}$ \\
\hline $3-18$ & $999.16 \mathrm{~A}$ & $1284.29 \mathrm{~A}$ & $1423.88 \mathrm{~A}$ \\
\hline $17-18$ & $1876.90 \mathrm{~A}$ & $2171.59 \mathrm{~A}$ & $2323.013 \mathrm{~A}$ \\
\hline $17-27$ & $919.75 \mathrm{~A}$ & $1168.33 \mathrm{~A}$ & $1292.17 \mathrm{~A}$ \\
\hline
\end{tabular}

Figure 12, depicts the overall overloading incidents for transmission line 3-18 after assuming wind gradients of $2 \mathrm{~m} / \mathrm{s}, 6 \mathrm{~m} / \mathrm{s}$ and $9 \mathrm{~m} / \mathrm{s}$.

As illustrated in Figure 12, line overloading incidents for line 3-18 has significantly decreased. For example, when $2 \mathrm{~m} / \mathrm{s}$ wind speed was assumed it has indicated a total of 63 overloading incidents for summer conditions which is a significant improvement compared to no DLR scenario. This highlight the fact that if multiple wind speeds were considered along a line even at wind speed of $2 \mathrm{~m} / \mathrm{s}$, there will be a significant improvement in the line ampacity, and hence allow more power to be dispatched safely without the need for wind power curtailment. The ideal and winter ambient conditions proved to be the most effective when $9 \mathrm{~m} / \mathrm{s}$ was assumed at the line. Summer and spring conditions have shown overloading incidents at $9 \mathrm{~m} / \mathrm{s}$, while indicating the necessity for a more conservative assumption with regard to ambient temperature.

The combination of wind farms operating in the network is a significant factor for line overloading. When wind generators were connected at buses 17, 27 and 18, line overloading incidents were still reported at $9 \mathrm{~m} / \mathrm{s}$. This demonstrates the fact that performance of the DLR will vary greatly depending on the location and power dispatched from wind farms.

\subsection{Power Loss Reduction using DLR}

The dynamic line ratings calculated in Section 5.2 for lines 3-18, 17-27 and 17-18 at varying wind speeds were applied to the network in order to observe the percentage improvement in power losses for area 1. Similar to previous analysis, ideal, summer, spring and winter weather characteristics as outlined in Table 3 have been used, while every combination of wind farms on 
buses 1, 3, 18, 17 and 27 have been analysed. Optimal power flow algorithm in the DIgSILENT Power Factory has been utilised in order to determine the power loss improvement. In addition, a number of different combinations of transmission lines were analysed in order to determine the optimal combination. The effect of DLR on overall system losses was analysed through its implementation on individual lines. Initially, ideal wind conditions were assumed whereby the wind speed at the wind farm was also assumed to be experienced at the transmission line. The results represent $100 \%$ load demand scenario. Figure 13 depicts the overall variation of network power losses when DLR was applied to transmission line 17-27.

Of the three lines chosen for these tests, line 17-27 proved to have the highest positive impact on the overall power losses within the system. As it can be seen, even at a dispatch power of 0 MW (which is equivalent to $3 \mathrm{~m} / \mathrm{s}$ and is considered the cut-in speed), the overall system losses have indicated a minimum improvement of $3.5 \%$, which was found during the summer months. At maximum dispatch power, hence at highest wind speed, the power losses have improved by $6 \%$ at ideal weather conditions. This is due to the fact that minimal difference in ambient temperature used to calculate the seasonal rating conditions, hence the overall percentage change between them was minimal; however, an overall improvement can be seen for transmission line 17-27.

In comparison to other tests performed, the overall impact of applying DLR to line 3-18 was minimal, in fact it has increased the overall power losses within the system by approximately $0.2 \%$ at ideal conditions. This line may not be considered as a fundamental pathway within the network when power is to be exported to other regions of the network. This was an unexpected result, as it has indicated the highest overloading incidents from the tests performed in Section 5.2. By comparing these results to those found in the initial OPF tests, a generator on bus three proved to have a large impact on power losses, thereby applying DLR to this line would not improve the overall losses in the system. Figure 14 depicts the change in power loss when DLR was applied to line 17-18 only. As can be seen, the overall effect at any of the rating characteristics was minimal with an overall improvement of just under $0.1 \%$ at ideal conditions.

The results indicate that all lines do not have the same effect on reducing system power losses. The overall effect would be determined by the overall position of the transmission line in the network and also the overall position of the wind generator in relation to the dynamically rated transmission line. This highlight the fact that initial investigations are of paramount 
importance when determining the suitable DLR candidates to minimise energy losses in the network.

In addition, further investigations have been carried out with regard to system energy loss reduction while assuming line 17-27 is equipped with DLR capability. It is assumed that the annual wind power production of the wind farms is distributed according to the Weibul distribution. Therefore, according to energy loss analysis it has shown that $3.52 \%$ reduction in annual energy losses by utilising DLR capability in line 17-27.

\section{Conclusions}

This study has investigated the differences between the IEEE and the CIGRE line rating standards for calculating the current carrying capacity of overhead transmission lines. It has been determined that the convection cooling and solar heating calculations lead to major differences between two standards. In particular, the roughness factor used in the CIGRE standard causes a significant difference between the two line rating models, in particular during high wind conditions. The sensitivity analysis performed on the IEEE standard concluded that wind speed has the greatest impact on the final ampacity of a transmission line with an overall change of $115 \%$ when compared to base case wind speed condition of $0.5 \mathrm{~m} / \mathrm{s}$. The effect of wind speed was also directly related to the attack angle. These two components of the convection cooling equation will influence each other, while the greatest impact of wind speed occurs at an attack angle of $90^{\circ}$.

When DLR was applied to the New England 39 bus system, improvements have been shown with regard to overall line overloading incidents as well as in network power losses. In relation to DLR implementation, this study proves the fact that the DLR can be successfully implemented in order to mitigate congestion in rural transmission corridors as a result of high wind power penetration. Furthermore, the energy that could be saved per year could further justify the installation of DLR systems to existing transmission system infrastructure with high wind power penetration. 


\section{Appendices}

\section{Appendix A}

Note: All symbols are given according to the standard symbols in used in the dynamic line rating standards.

Ambient Temperature $\left(T_{a}\right)=35^{\circ} \mathrm{C}$; Maximum allowable conductor temperature $\left(T_{c}\right)=80$; Conductor Diameter $(D)=28.1 \mathrm{~mm}$, Elevation above sea level $\left(H_{e}\right)=0$, wind direction factor $(\phi)=$ 90; Solar absorptivity $(a)=0.5$; latitude $(\Phi)=30$; hour angle $(\omega)=-15^{\circ}$; Day of the year $=161$; Azimuth of the line $=90^{\circ}$. 


\section{References}

1. IEEE Standard for Calculating the Current-Temperature of Bare Overhead Conductors, IEEE Stand. 738, 2007.

2. CIGRE WG 22.12, The Thermal behaviour of overhead conductors - sections 1 and 2: mathematical model for evaluation of conductor temperature in the steady state and the application, Electra. 144 (1992), pp. 107-125.

3. N. P. Schmidt, Comparison between IEEE and CIGRE ampacity standards, IEEE Trans. Power Del. 14(4) (1999), pp. 1555-1562.

4. S. Abbott, S. Abdelkader, L. Bryans, D. Flynn, experimental validation and comparison of IEEE and CIGRE dynamic line models, In: Proc 45 th Universities Power Engineering Conference; 2010.

5. V. Hamidi, F. Robinson, Responsive demand in networks with high penetration of wind power, Transmission and Distribution Conferance and Exposition; 2008.

6. D. J. Burke and M. J. O'Malley, Factors influencing wind energy curtailment, IEEE Trans. Sustain Energy. 2(2) (2011), pp. 185-193.

7. A. Vergnol, V. Rious, J. Sprooten, B. Robyns, J. Deuse, Integration of renewable energy in the european power grid: market mechanism for congestion management, In:Proc $7^{\text {th }}$ International Conferance on the European Energy Market (EEM); 2010.

8. J. Heckenbergerová, P. Musilek, K. Filimonenkov, Quantification of gains and risks of static thermal rating based on typical meteorological year, Int J Electr Power Energy Syst. 44 (1) (2013), pp. 227-235.

9. J. Hosek, P. Musilek, E. Lozowski, P. Pytlak, Effect of time resolution of meteorological inputs on dynamic thermal rating calculations, IET Gene., Transmi. and Distri. 5(9) (2011), pp. 941-947.

10. J. Cunningham, J. Colandairaj, Methodology for applying real-time ratings to wood pole supported overhead lines, In: Porc 44th International Universities Power Engineering Conference; 2009.

11. M. W. Davis, A New thermal rating approach: the real time thermal rating system for strategic overhead conductor transmission lines part II, IEEE Trans. Power Apparatus and Syst. 96(3) (1977), pp. 810-825.

12. A. McLaughlin, Application of dynamic line rating to defer transmission network reinforcement due to wind generation, In:Proc $46^{\text {th }}$ International Universities Power Engineering Conference; 2011.

13. S. Abdelkader, S. Abbott, J. Fu, B. Fox, D. Flynn, L. McClean, and L. Bryans, Dynamic monitoring of overhead line ratings in wind intensive areas, In: Proc European wind energy conference; 2009.

14. M. Matus, D. Sáez, M. Favley, C. Suazo-Martinez, J. Moya, G. Jiménez-Estévez, R. PalmaBehnke, G. Olguín, P. Jorquera, Identification of critical spans for monitoring systems in dynamic thermal rating, IEEE Trans. Power Deli. 27(2) (2012), pp. 1002-1009.

15. Y. Du, Y. Liao, On-line estimation of transmission line parameters, temperature and sag using PMU measurements, Electric Power Syst. Research, 93(2012), pp. 39-45.

16. L. Meegahapola, S.R. Abbott, D.J. Morrow, T. Littler, D. Flynn, Optimal allocation of distributed reactive power resources under network constraints for system loss minimization, IEEE Power Engineering Society General Meeting; 2011.

17. D. A. Douglas, Weather-dependant versus static thermal line rating, IEEE Trans. Power Del. 3(2) (1988), pp. 742-753. 
18. B. W. Brennan, Dynamic Line Ratings for Cowlitz-LaGrande Transmission Line, Washington, USA, 2008.

19. ACSR Conductor Data Sheet. Media cables, 2011. [online], Available: http://www.midalcable.com/DataSheets/ACSR-metric.PDF.

20. GE Energy. Dynamic Modelling of GE 1.5 and 3.6 Wind Turbine-Generators; 2003.

21. AEMO, Transmission Equipment Ratings. [online]. Available:

http://www.aemo.com.au/Electricity/Data/Network-Data/Transmission-EquipmentRatings. 